\title{
Internal aeration and respiration of submerged tomato hypocotyls is enhanced by ethylene-mediated aerenchyma formation and hypertrophy
}

\author{
Mignolli Francesco ${ }^{\mathrm{a}, \mathrm{c}}$, Juan Santiago Todaro ${ }^{\mathrm{b}}$ and María Laura Vidoz, ${ }^{\mathrm{a}, \mathrm{c},}$ \\ anstituto de Botánica del Nordeste (IBONE), UNNE-CONICET, Corrientes, Argentina \\ ${ }^{\mathrm{b}}$ Facultad de Medicina, Universidad Nacional del Nordeste (UNNE), Corrientes, Argentina \\ 'Facultad de Ciencias Agrarias, Universidad Nacional del Nordeste (UNNE), Corrientes, Argentina
}

\section{Correspondence}

${ }^{*}$ Corresponding author,

e-mail: malauravidoz@gmail.com

With the impending threat that climate change is imposing on all terrestrial ecosystems, plants' ability to adjust to changing environments is, more than ever, a very desirable trait. Tomato (Solanum lycopersicum L.) plants display a number of responses that allow them to survive under different abiotic stresses such as flooding. We focused on understanding the mechanism that facilitates oxygen diffusion to submerged tissues and the impact it has on sustaining respiration levels. We observed that, as flooding stress progresses, stems increase their diameter and internal porosity. Ethylene triggers stem hypertrophy by inducing cell wall loosening genes, and aerenchyma formation seems to involve programmed cell death mediated by oxygen peroxide. We finally assessed whether these changes in stem morphology and anatomy are indeed effective to restore oxygen levels in submerged organs. We found that aerenchyma formation and hypertrophy not only increase oxygen diffusion towards the base of the plant but also result in an augmented respiration rate. We consider that this response is crucial to maintain adventitious root development under such conditions and, therefore, making it possible for the plant to survive when the original roots die.

\section{Introduction}

This article has been accepted for publication and undergone full peer review but has not been through the copyediting, typesetting, pagination and proofreading process which may lead to differences between this version and the Version of Record. Please cite this article as doi: $10.1111 / \mathrm{ppl} .13044$ 
The more we study plants, the more amazed we are at the ability of these seemingly simple organisms to adjust their morphology and physiology to the numerous and changing environmental cues to which they are exposed in their lifetime. Yet, an insidious threat for plants -but not only- is emerging and, unless effective measures are taken to mitigate climate change, its impact on ecosystems worldwide could be catastrophic.

One of the consequences of global warming is the enhancement of water fluxes, meant as evaporation and precipitation. This phenomenon has led to an intensification of extreme events, such as droughts and floods, in an increasing proportion of the planet where dry regions get drier and wet regions, wetter (Durack et al. 2012). According to FAO's report about natural disasters in 48 developing countries of Africa, Asia and Latin America during the 2003-2013 decade, agriculture represents 25\% of all damage and losses caused by climate-related threats, with an impact of about USD 30 billion. The crop subsector appeared the most affected, especially by floods and storms that caused almost 60 and $23 \%$ of the total losses, respectively (FAO 2015).

In spite of being an essential molecule for all living organisms, water, when in excess, dramatically hampers gas exchange since gas solubility in a water-saturated ambient is 10000 times less than in air. Limited gas availability for submerged tissues causes a reduction of chloroplast $\mathrm{CO}_{2}$ intake and low $\mathrm{O}_{2}$ diffusion into mitochondria, which impedes vital biochemical processes such as photosynthesis and respiration, respectively (Colmer and Voesenek 2009). Differently from animals in which oxygen is actively transported throughout the organism, plants lack such mechanism (van Dongen and Licausi 2015) and, consequently, rely on adaptive traits and acclimation responses that tend to avoid radial oxygen loss (by creating suberin/lignin barriers) or facilitate gas diffusion to -and ventilation from- submerged tissues. In the latter case, the development of aerenchyma, a porous tissue, makes it possible to establish a connection between air-filled spaces of submerged organs with those from emerging ones, improving gas circulation. In addition, the formation of aerenchyma reduces the number of respiring cells lowering oxygen consumption (Voesenek and Bailey-Serres 2015). According to a thorough classification of aerenchymatous tissues in many wetland plants by Seago et al. (2005), aerenchyma development follows one of three distinct patterns known as lysigeny, schyzogeny and expansigeny. Lysigenous aerenchyma is characterized by the formation of lacunae originated by the collapse of particular groups of cells. Schyzogenous aerenchyma is often constitutive in plants adapted to flood prone areas. In this case, air chambers are originated by a coordinated cell division/expansion along the radii of the stem or root cortex. 
Finally, in expansigenous aerenchyma, the enlargement of intercellular spaces as a consequence of cell expansion can, in some cases, originate honeycomb-like structures that facilitate submerged tissue ventilation (Seago et al. 2005).

Along with the perception of oxygen deficiency, ethylene build-up is considered one of the earliest signals that prompt a flooding acclimation response in most plants. In fact, due to its gaseous nature, ethylene can hardly diffuse in water causing the hormone to be entrapped in the proximity of submerged tissues. The accumulation of ethylene up to physiologically saturating levels frequently induces responses in submerged organs (Sasidharan and Voesenek 2015). For instance, ethylene has been considered the major player that triggers programmed cell death (PCD) during aerenchyma formation through the action of reactive oxygen species (ROS) (Drew et al. 2000, Mergemann and Sauter 2000, Visser and Voesenek 2004, Ni et al. 2019). In rice, ethylene participates in the modulation of NADPH oxidase genes (RBOH, Respiratory Burst Oxidase Homolog) involved in ROS production (Yamauchi et al. 2017). In addition, the ethylene-mediated repression of the MT2 gene, a metallothionein involved in ROS scavenging, strongly contributes to elevate the hydrogen peroxide content and trigger the death of specific cortical cells in rice (Steffens et al. 2011). Cell death during lysigenous aerenchyma formation is known to proceed following an apoptosis sequence. In maize roots, a sequence of cellular events such as chromatin condensation, nuclear DNA fragmentation, membrane invagination and vesicle formation take place shortly after the onset of hypoxia treatment (Gunawardena et al. 2001). Cell breakdown is considered the ultimate event during aerenchyma formation and involves the action of several cell wall loosening enzymes such as expansins, xyloglucan endo-transglycosylase (XET) and cellulases (Jackson and Armstrong 1999). Besides the formation of aerenchyma, hypertrophic stem cell growth has been observed in several plants exposed to flooding stress (Wample and Reid 1978, Pires et al. 2002, Argus et al. 2015, Vidoz et al. 2016). In some plants, stem enlargement is associated with cortical cracks and hypertrophied lenticels which are shown to facilitate the connection between the atmosphere and the underwater hypoxic tissues (Shimamura et al. 2010, Larré et al. 2013).

Tomato plants are considered to be susceptible to flooding stress (Bradford 1983, McNamara and Mitchell 1990, Bhatt et al. 2015). However, several adaptive responses allow them to mitigate the deleterious effect of root hypoxia. Among them, adventitious roots emerging from the base of submerged stems are able to efficiently substitute the seminal roots that die in hypoxic soils (Else et al. 2009, Vidoz et al. 2016). As far as we know, aerenchyma formation in submerged tomato stems has only been reported by Kawase and 
Whitmoyer (1980) and Kawase (1981). These authors observed that the formation of an aerenchymatous tissue in flooded tomato stems was associated with ethylene-promoted cortical cell collapse. Nevertheless, no further studies were performed and the exact mechanism that underlies the formation of aerenchyma and stem hypertrophy in submerged tomato stems has not been tackled yet.

Here we show that, concomitantly with aerenchyma formation, hypertrophic stem cell growth takes place in flooded hypocotyls as a result of ethylene-mediated induction of several cell wall relaxation genes. Moreover, the observed burst of hydrogen peroxide is likely involved in ROS-mediated PCD induction of cortical cell collapse. We finally demonstrate that ethylene-induced aerenchyma, in combination with cortex cell enlargement, is enough to re-establish adequate oxygen levels, boosting underwater hypocotyl respiration.

\section{Materials and methods}

\section{Plant materials and treatments}

Tomato (Solanum lycopersicum L.) seeds of the cv. Ailsa Craig (AC, accession $\mathrm{n}^{\circ}$ LA2838A), Pearson (accession $n^{\circ}$ LA0012) and the mutant Never ripe (Nr, accession $n^{\circ}$ LA0162, with Pearson as background) were obtained from the Tomato Genetics Resource Center (TGRC, University of California, Davis, CA, USA). Plants were grown in a climatic room at $26 \pm 2{ }^{\circ} \mathrm{C}, 50-70 \%$ of relative humidity and $254 \mathrm{~mol}^{-2} \mathrm{~s}^{-1}$ of light intensity, with a $15 \mathrm{~h}$ photoperiod (provided by high pressure sodium lamps Vialox ${ }^{\circledR}$, 400W, OSRAM). Seedlings were regularly watered with $1 / 4$ strength Hoagland's solution (Hoagland and Arnon 1938). Plants were allowed to grow for 4 weeks after the sowing date before being used in experiments. Flooding treatments were carried out in plastic containers (60 cm high, $40 \mathrm{~cm}$ wide and $25 \mathrm{~cm}$ deep), by submerging the plants with tap water up to their cotyledonary nodes. Ethylene inhibitors [silver nitrate $\left(\mathrm{AgNO}_{3}, 100 \mu \mathrm{M}\right.$, Sigma Aldrich), cobalt chloride $\left(\mathrm{CoCl}_{2} \cdot 6 \mathrm{H}_{2} \mathrm{O}, 500 \mu \mathrm{M}\right.$, Sigma Aldrich) and aminooxyacetic acid (AOA, $500 \mu \mathrm{M}$, Sigma Aldrich) (Beyer, 1976, Bradford et al. 1982)] as well as the synthetic auxin 1-Naphtaleneacetic acid (NAA, $100 \mu \mathrm{M}$, Sigma Aldrich), the auxin transport inhibitor 2,3,5-Triiodobenzoic acid (TIBA, $500 \mu \mathrm{M}$, Sigma Aldrich) and the ethylene releasing compound 2Chloroethylphosphonic acid (Ethrel ${ }^{\circledR} 48 \mathrm{SL}, 500 \mu \mathrm{M}$, Bayer) were applied by brushing hypocotyls with aqueous solutions containing $0.01 \%$ Triton $\mathrm{X}$, both 24 and $8 \mathrm{~h}$ before the onset of flooding treatments. Hypocotyl samples were collected at different time points as specified for each experiment. In the case of 
samples used for gene transcription analysis, hypocotyl portions were excised and immediately frozen at $70^{\circ} \mathrm{C}$ until processed.

\section{Hypocotyl anatomy}

We followed the method described by Vidoz et al. (2016). Hypocotyl sections of control, flooded and $\mathrm{AgNO}_{3}$-treated flooded plants, were fixed in FAA (10 formaldehyde 40\%: 5 acetic acid: 50 ethanol: 35 water $\mathrm{v} / \mathrm{v}$ ) by generating vacuum for $15 \mathrm{~min}$. Samples were sequentially dehydrated with tertiary butyl alcohol series and finally embedded in paraffin. Finally, $30 \mu \mathrm{m}$ sections were obtained with a microtome, stained with safranine for $2 \mathrm{~h}$ and successively observed with an optical microscope (Leica DM LB2, Leica Microsystems). Three biological replicates were processed for each treatment and 20 sequential sections for each replicate were observed. Representative pictures were then acquired with a digital camera Leica ICC50 HD. These sections were used to obtain measurements of cortex cell area, cortex cell density and area of cortex cells with the open source software ImageJ (NIH, http://rsb.info.nih.gov/ij).

\section{Porosity and diameter measurement}

Hypocotyl porosity measurements at different times after the start of flooding stress were obtained by following the pycnometer method described by Vidoz et al. (2016). Hypocotyl diameters were measured with a digital micrometer (Digimatic micrometer MDC-25SX, Mitutoyo).

\section{Gene expression analysis}

For total RNA extraction and subsequent gene expression analysis we followed the method described by Vidoz et al. (2016). Primers used for real time PCR were: LeEF1 $\alpha$ (elongation factor 1-alpha, X53043) primer Fw 5'-CATCAGACAAACCCCTCCGT-3', Rv 5'-GGGGATTTTGTCAGGGTTGTAA-3'; LeEXP1 (expansin, NM_001247029) primer Fw 5'-TTGACCTCGCTATGCCTATG-3', Rv 5'CTGATTCCTCCTTGCTTTCG-3'; LeEXP2 (expansin, AF096776) primer Fw 5'CCTCCTCTCCAACATTTTGATT-3', Rv 5'-CTTCGAAAAGATACAGGGACGA-3'; SIXTH1 (endoxyloglucan transferase, NM_001246929) primer Fw 5'-TTTTTGGGGAACAGAACTGG-3', Rv 5'ATGGTAGCCCTTGGTTGGAT-3’; Cel7 (endo-1,4-beta-D-glucanase, NM_001247394) primer Fw 5'CGACTCTCTTGGAGGGGTAA-3', Rv 5’-TGCCATTGGGAAATTGAACT-3’; SlCycB1 (cyclin B1, 

AJ243454)
primer
FW
5'-GCACCACACTGGATACACAGA-3',
$\mathrm{Rv}$
5'- AAGAGGGCAACAGCACATCT-3’.

\section{TUNEL assay}

Hypocotyl sections from control, flooded and $\mathrm{AgNO}_{3}$-treated flooded plants were collected. Hypocotyl segments of about $5 \mathrm{~mm}$ were infiltrated under vacuum in $4 \%(\mathrm{w} / \mathrm{v})$ paraformaldehyde dissolved in phosphate buffer saline (PBS) $\mathrm{pH} 7.4$ and left overnight at $4^{\circ} \mathrm{C}$. Following, ten sections from three biological replicates of each treatment were dehydrated using sequential water/ethanol solutions (from 10 to $100 \%$ ethanol) and then embedded in paraffin. Hypocotyl sections of $30 \mu \mathrm{m}$ were obtained with a microtome and subsequently subjected to the TUNEL assay using the kit DeadEnd ${ }^{\mathrm{TM}}$ Fluorometric TUNEL System (Promega) according to the manufacturer instructions. Positive controls consisted of permeabilized sections incubated with 10 units $\mathrm{ml}^{-1}$ DNase I for $10 \mathrm{~min}$.

\section{Evans blue staining}

The staining followed the method described by Mergemann and Sauter (2000) with some modifications. Excised hypocotyls from control, flooded and $\mathrm{AgNO}_{3}$-treated flooded plants were hand cut in thin slices (approximately $1 \mathrm{~mm}$ ) and left in a 1\% (w/v) Evans blue solution for $2 \mathrm{~min}$. After rinsing five times with distilled water, representative sections from five biological replicates for each treatment were photographed under a stereomicroscope (Leica S6E, Leica Microsystems).

\section{Hydrogen peroxide localization in hypocotyls}

Local accumulation of hydrogen peroxide $\left(\mathrm{H}_{2} \mathrm{O}_{2}\right)$ in control and flooded hypocotyl sections was observed according to Liu et al. (2014). Stripes of nylon membrane (Zeta-Probe ${ }^{\circledR}$ Blotting Membranes, BIO-RAD) were imbibed in a $5 \mathrm{mg} \mathrm{ml}^{-1}$ aqueous solution of 3,3'-diaminobenzidine (DAB), $\mathrm{pH}$ 3.8. After drying at room temperature, stripes were used for tissue printing. Three transversal sections from three biological replicates of control and flooded hypocotyls were cut, immediately blotted onto the stripe and held for 10 s. Sections were then removed and stripes were washed in 95\% ethanol to eliminate pigment stains. Blots were finally photographed under a stereomicroscope.

\section{Determination of oxygen content in hypocotyls}


Concentration of oxygen in hypocotyls was measured with fixed needle-type oxygen sensors OXF500PT connected to the optical oxygen meter FirestingO $\mathrm{O}_{2}$ (PyroScience $\left.\mathrm{GmbH}\right)$. The sensor was mounted on a manual micromanipulator MM33 (PyroScience $\mathrm{GmbH}$ ) to deepen the needle tip $0.5 \mathrm{~mm}$ below the hypocotyl epidermis into the cortex. For each hypocotyl, a mean of 4 measurements was recorded.

\section{Respiration measurements}

Hypocotyl segments of control and flooded plants about 1.5-cm long (approx. $0.3 \mathrm{~g}$ ) were immersed in distilled water in $4 \mathrm{ml}$ HPLC vials with Teflon septa caps. Dissolved oxygen was measured before (T0) and after incubation at $37^{\circ} \mathrm{C}$ for $1 \mathrm{~h}(\mathrm{Tf})$ with a retractable oxygen microsensor OXR50 connected to the Firesting $\mathrm{O}_{2}$ oxygen meter. An external temperature sensor TDIP15 (PyroScience GmbH) was used to provide instantaneous temperature compensation during oxygen measurements. Oxygen consumption was calculated as the difference in concentration between $\mathrm{Tf}$ and $\mathrm{T} 0$ and expressed as $\mu \mathrm{mol} \mathrm{O}_{2} \mathrm{~g}^{-1} \mathrm{FW} \mathrm{h}^{-1}$.

\section{Histochemical assay of cytochrome c oxidase (COX) activity}

The method is based on the COX-mediated oxidation of DAB and was performed according to Attallah et al. (2011) with minor modifications. Hypocotyls of control and flooded plants were hand cut in 1-mm slices and fixed at $4^{\circ} \mathrm{C}$ for $1 \mathrm{~h}$ in a solution of $2 \%$ paraformaldehyde, $2 \%$ polyvinylpyrrolidone (PVP), 1 $\mathrm{mM}$ dithiothreitol (DTT) and $5 \mathrm{mM}$ ascorbic acid, $\mathrm{pH}$ was adjusted to 7.0. Hypocotyl sections were rinsed and incubated in a staining solution (100 mM sodium phosphate, $100 \mathrm{mM}$ sucrose, $1.4 \mathrm{mM}$ DAB, $\mathrm{pH}$ 7.0) for $4 \mathrm{~h}$ at $37^{\circ} \mathrm{C}$. Staining solutions without $\mathrm{DAB}$ and with the addition of $5 \mathrm{mM}$ potassium cyanide, a COX inhibitor, were used as negative controls.

\section{Results}

\section{Ethylene perception is required for aerenchyma formation in flooded tomato stems}

In order to evaluate ethylene involvement in aerenchyma formation and the best treatment to locally block its effect, we first measured the porosity -volume occupied by air- of flooded stems with and without the previous application of an ethylene biosynthesis or perception inhibitor (Fig. 1A). We observed that porosity development in flooded hypocotyls was twice as much as in control plants, and that this response could be most effectively prevented by the topical application of $\mathrm{AgNO}_{3}$. Since $\mathrm{Co}^{2+}$ caused a minor 
reduction in flooded stem porosity and $\mathrm{AOA}$ was ineffective, we used $\mathrm{AgNO}_{3}$ to block ethylene perception in subsequent experiments.

Following, we measured porosity for 6 days after the onset of flooding in control, flooded and $\mathrm{AgNO}_{3}$ treated flooded plants (Fig. 1B). Although porosity increased in all flooded plants, those pretreated with the inhibitor had significantly less porosity and only reached untreated plants levels after 6 days of flooding, probably because the $\mathrm{AgNO}_{3}$ treatment was no longer effective.

Ethylene involvement in stem porosity during flooding was confirmed by using the $\mathrm{Nr}$ mutant, which is partially insensitive to ethylene (Lahanan et al. 1994; Fig. 1C). Whereas there was a significant increase in porosity in flooded wild type stems, porosity levels in $\mathrm{Nr}$ remained unchanged even after 6 days of flooding.

Considering that flooded tomato plants show morphological changes within the first days from the start of flooding, we observed the anatomy of tomato stems during the first $72 \mathrm{~h}$ in control, flooded and $\mathrm{AgNO}_{3}$ treated flooded plants (Fig. 2). While there were no significant changes in control hypocotyls, the cortex of flooded stems was characterized by an increased loosening after $48 \mathrm{~h}$ of submersion, which resulted in evident empty spaces after only $72 \mathrm{~h}$. Moreover, these anatomical changes were accompanied by the enlargement of spherical cells starting after $24 \mathrm{~h}$ of flooding. In contrast, hypocotyl treatment with $\mathrm{AgNO}_{3}$, which locally inhibited ethylene perception, completely prevented these responses.

\section{Programmed cell death results in lysis of cortical cells}

The TUNEL assay has been widely used to detect the DNA fragmentation, which is one of the hallmarks of PCD (Gunawardena et al. 2001). Based on the role of ethylene as a PCD trigger, we performed TUNEL staining in control, flooded and flooded plants previously treated with $\mathrm{AgNO}_{3}$ (Fig. 3), collecting material

$72 \mathrm{~h}$ after the onset of the experiment. Stems treated with $\mathrm{AgNO}_{3}$ were similar to control ones, showing very few nuclei stained with TUNEL. However, numerous cortical cell nuclei were stained in stems harvested from flooded plants, coinciding with the region and environmental condition in which aerenchyma is formed.

Following the TUNEL staining, we used Evans blue dye to identify dead cells in stem tissues in control, flooded and $\mathrm{AgNO}_{3}$-treated flooded plants after $72 \mathrm{~h}$ from the start of the experiment (Fig. 4A-C). In agreement with the previous observations, flooded stems had more stained cortical cells than control and $\mathrm{AgNO}_{3}$-treated ones, suggesting that TUNEL-positive nuclei effectively corresponded to cells that would 
have undergone PCD. Interestingly, during the formation of aerenchyma, also adventitious roots started to grow inside stem tissues and there was epidermal cell death adjacent to the emerging root tips (Fig. 4D-I).

\section{$\mathrm{H}_{2} \mathrm{O}_{2}$ is produced in cortical cells of flooded stems}

Considering that, besides ethylene, ROS are frequently associated with aerenchyma development, we used DAB staining to assess $\mathrm{H}_{2} \mathrm{O}_{2}$ formation in control and flooded stems (Fig. 5A). After $24 \mathrm{~h}$ of flooding, $\mathrm{H}_{2} \mathrm{O}_{2}$ presence was revealed in epidermal and cortical cells and increased after $48 \mathrm{~h}$ from the onset of the treatment. Remarkably, staining intensity started to decrease in stems after $72 \mathrm{~h}$ of flooding.

In order to confirm the involvement of ROS in early stages of aerenchyma formation, we also analyzed SIRBOH1 transcript abundance. Consistent with DAB staining observations, SIRBOH1 transcripts were more abundant (approximately 4 times) in flooded stems than in control ones (Fig. 5B) after $4 \mathrm{~h}$ of flooding. Moreover, SIRBOH1 levels in flooded stems remained higher than in control tissues for up to 12 h. Interestingly, $\mathrm{AgNO}_{3}$ treatment almost completely suppressed SIRBOH1 gene expression in flooded stems.

\section{Stem hypertrophy occurs concomitantly with aerenchyma formation}

Together with porosity development, flooded stems are characterized by an increase in diameter within the first few days after the onset of flooding. Interestingly, although an excess of ethylene applied exogenously as ethephon had no further effect on hypertrophy, the inhibition of ethylene perception through $\mathrm{AgNO}_{3}$ application blocked cell expansion in stems (Fig. 6A).

Following, we studied the development of hypertrophy after several days of flooding treatment (Fig. 6B). It was possible to observe that flooded $\mathrm{AgNO}_{3}$-treated stems always remained thinner than untreated ones, but both were wider than stems from control plants (Fig. 6B). Even though the $\mathrm{Nr}$ mutant showed low stem porosity upon flooding, it behaved similarly to its wild type regarding hypertrophy, suggesting that these adaptive responses are differently regulated (Fig. 6C).

In order to confirm that increases in stem diameter are caused by cell expansion, relative expression levels of four genes encoding cell wall loosening enzymes were studied (Fig. 7). It was observed that, after only $4 \mathrm{~h}$ of flooding, there was an increase in LeEXP1, LeEXP2 (Expansin), SIXTH1 (Endo-Xyloglucan Transferase) and Cel7 (Endo-1,4-beta-D-glucanase) transcripts number followed by a decrease after $8 \mathrm{~h}$ in LeEXP1 and Cel7, whereas LeEXP2 and SIXTH1 remained upregulated. This early induction was not 
observed in control or flooded plants previously treated with $\mathrm{AgNO}_{3}$ where stem hypertrophy occurred to a lower extent.

Moreover, we explored whether the 2-fold increase in flooded stems area (Fig. 8A) involved cell division besides cell expansion. In flooded hypocotyls, cortical cell density (cell $\mathrm{n}^{\circ} \mathrm{mm}^{-2}$ ) was barely half of controls but cells were twice as large as control ones (Fig. 8B-C). In addition, SlCycB1 expression level, which has been previously used as a cell division marker (Ivanchenko et al. 2013, Liu et al. 2016), was lower in flooded hypocotyls than in control ones, further confirming that stem hypertrophy is independent from cell division (Fig. 8D).

\section{Increased internal aeration enhances respiration in submerged hypocotyls}

With the aim to assess whether aerenchyma formation contributes to the diffusion of oxygen towards submerged tissues, we measured internal oxygen concentration with a microsensor. Data revealed that flooding caused a drop in oxygen levels after one day of treatment (Fig. 9A). Interestingly, although aeration increased in flooded hypocotyls reaching the same level as controls after 3 days, it remained low in those previously treated with $\mathrm{AgNO}_{3}$. Following, we measured oxygen uptake in hypocotyls to evaluate whether improved aeration of submerged tissues was accompanied by an increase in respiration (Fig. 9B). Indeed, oxygen consumption in flooded hypocotyls was higher not only than in $\mathrm{AgNO}_{3}$-treated flooded hypocotyls but also than in control ones. Hypocotyl sections of control and flooded plants were assayed for COX activity in order to visualize the regions of the stem that present a higher oxygen requirement (Fig. 9C). The DAB staining revealed intense COX activity in cambium and vascular tissues of both control and flooded stems. Elongating adventitious root primordia showed particularly high levels of DAB oxidation, which was abolished when stems were incubated in presence of the COX inhibitor KCN (Fig. 9C).

\section{Discussion}

When plants are exposed to flooding events, submerged tissues are suddenly deprived of normal levels of oxygen. This change in the surrounding environment triggers a number of adaptive responses that determine the ability of a plant to survive such stress (Voesenek and Bailey-Serres 2015). In this sense, the maintenance of oxygen diffusion towards submerged organs is crucial for their normal functioning, growth and ultimate survival (Jackson and Drew 1984). In this paper, we have shown that tomato plants 
are able to effectively improve internal aeration in submerged stems via ethylene-mediated aerenchyma formation and cortical cell expansion. Similar to a previous report (McNamara and Mitchell 1990), we have observed that there is a 4-fold increase in stem hypertrophy (Fig. 6A,B) and porosity of submerged stems (Fig. 1B). However, when ethylene perception is effectively blocked, both morpho-anatomical changes are drastically reduced suggesting that this hormone plays a major role in tomato aerenchyma formation (Figs 1A,B, 2 and 6A,B; Kawase and Whitmoyer 1980, Shiono et al. 2008, Vidoz et al. 2016). Along with $\mathrm{AgNO}_{3}$, porosity was significantly reduced with $\mathrm{CoCl}_{2}$ treatment but no effect was observed after AOA application (Fig. 1A). Since AOA and $\mathrm{Co}^{2+}$ ions are inhibitors of ACC synthase and ACC oxidase respectively (Bradford et al. 1982), we believe that ethylene production from ACC is the limiting step under flooding, which appears logical due to oxygen requirement for ACO oxidase to function (Jackson 2002, Argueso et al. 2007). The $N r$ mutant is known for having a defective ETR3 ethylene receptor (Lahanan et al. 1994). When flooded, $\mathrm{Nr}$ shows reduced adventitious root number but higher above ground biomass (Vidoz et al. 2010, 2016). In line with the role of ethylene perception in aerenchyma formation in tomato so far described, the $\mathrm{Nr}$ mutation reduces porosity in hypocotyls exposed to flooding (Fig. 1C). However, it is worth noting that stem hypertrophy is not affected in the mutant (Fig. 6C), leading to the idea that only ethylene-induced aerenchyma formation proceeds through the ETR3 (Ethylene Response 3)-mediated ethylene signalling pathway and both responses are therefore differentially regulated. Differently from rice, in which the constitutive expression of an ethylene biosynthesis gene is responsible for aerenchyma formation under aerobic conditions (Yamauchi et al. 2016), ethylene biosynthesis in tomato is triggered only in response to flooding (Vidoz et al. 2010). Moreover, exogenous ethylene (applied as ethephon) does not promote stem enlargement under aerated conditions (Fig. 6A) indicating that, as in many non-wetland species, aerenchyma is triggered by hypoxia through the action of ethylene (Yamauchi et al. 2018).

When aerenchyma development is analysed over time, it is possible to observe that cortical cells undergo an early swelling before cell lysis takes place (Fig. 2). Indeed, as cortex area increases, cortex cell density is reduced and average volume of cells increases (Fig. 8A-C). In addition, the equal or lower expression of the cell cycle marker SlCycB1 gene (Fig. 8D) and the upregulation of cell wall loosening genes (LeEXP2, SIXTH1, and Cel7; Fig. 7) in flooded hypocotyls indicate that cortical parenchyma is subjected to a cell expansion -but not cell division- process. It is thus suggested that, in combination with cell death, cell 
expansion might contribute to the ventilation of submerged hypocotyls by increasing intercellular spaces in the cortex (Seago et al. 2005).

PCD triggered by environmental or developmental signals is known to be mediated by ethylene (Lombardi et al. 2007, Petrov et al. 2015). Similar to other species (Gunawardena et al. 2001, Joshi and Kumar 2012, Ni et al. 2019), aerenchyma formation in tomato is achieved via ethylene-mediated PCD of subepidermal and cortical cells (Figs 3 and 4A-C). In this sense, TUNEL staining was observed in flooded stems unless ethylene action is blocked (Fig. 3), suggesting that an initial degradation of nuclear DNA precedes nucleus autolysis (Drew et al. 2000). Cell death also occurs in cortical cells proximal to adventitious root primordia (Fig. 4D-I) preventing damages to the root tip as it grows across cortical tissues (Mergemann and Sauter 2000).

ROS involvement in aerenchyma formation has been widely described in rice and recently in sunflower (Parlanti et al. 2011, Steffens et al. 2011, Yamauchi et al. 2017 and Ni et al. 2019). In tomato, we detected a transient presence of $\mathrm{H}_{2} \mathrm{O}_{2}$ in submerged tissues suggesting its role as a signal molecule (Fig. 5A). In addition, the SIRBOH1 gene is upregulated in response to flooding only when plants fully perceive ethylene (Fig. 5B), which indicates that $\mathrm{H}_{2} \mathrm{O}_{2}$ could mediate aerenchyma formation through ethylene signalling (Steffens and Sauter 2009, Yamauchi et al. 2014).

The ultimate requirement of flooded plants to survive is to facilitate oxygen diffusion to submerged tissues. Our measurements of oxygen concentration confirm that the morpho-anatomical changes studied in this paper are effective to re-establish oxygen levels in cortical cells (Figs 9A and 10). Moreover, we went further in verifying the effectiveness of aerenchyma and hypertrophy to restore respiration in submerged tissues. When aerenchyma formation is prevented by $\mathrm{AgNO}_{3}$-treatement, there is a steeper reduction in oxygen consumption and, therefore, respiration (Fig. 9B, C), revealing the extent to which air-filled spaces are able to sustain oxygen flow and respiratory metabolism. Surprisingly, oxygen uptake is higher in submerged hypocotyls with respect to those from plants grown in an aerobic environment, and flooded plants without aerenchyma sustain a respiration rate similar to control plants (Fig. 9B, C). Considering that one of the most dramatic events that take place in flooded plants is the death of the original root system, the replacement of these with adventitious roots is essential for survival (Vidoz et al. 2016). The growing primordia depend on an adequate oxygen supply to sustain respiration and, consequently, the accelerated growth rates that allow them to emerge soon after the onset of flooding (Figs 9D and 10). 
Oxygen availability in submerged tissues is enhanced not only by reducing the number of respiring cells (Zhu et al. 2010) but also by several metabolic adjustments that take place to save oxygen, such as ethanolic and alanine fermentation, and the reduction of oxygen-consuming enzyme activity (Zabalza et al. 2009, Rocha et al. 2010, Shingaki-Wells et al. 2014, Loreti et al. 2016). Yet, evidence seems to indicate that the internal oxygen concentration in submerged hypocotyls of tomato is sufficient to maintain respiration regardless of increased porosity. However, respiration is boosted by the formation of aerenchyma and stem hypertrophy. Further experiments are being carried out in order to gain insight into these findings.

\section{Author contributions}

F.M. and M.L.V. designed the experiments; F.M. performed experiments in Fig. 1, 2, 6, 7, 8, 9; J.S.T. carried out experiments in Fig. 3; M.L.V. performed experiments in Fig. 4 and 5; M.L.V. and F.M. wrote the paper.

Acknowledgements — We would like to thank Dr. Ana María González for allowing us to use the Plant Anatomy Laboratory for microscopic analysis. We also thank Mr. Pierino Mignolli for his invaluable assistance. This work was supported by grants from ANPCyT (Agencia Nacional de Promoción Científica y Tecnológica) and UNNE (Universidad Nacional del Nordeste).

\section{Data availability statement}

The data that support the findings of this study are available from the corresponding author upon reasonable request.

\section{References}

Argueso CT, Hansen M, Kieber JJ (2007) Regulation of ethylene biosynthesis. J Plant Growth Regul 26: 92-105

Argus RE, Colmer TD, Grierson PF (2015) Early physiological flood tolerance is followed by slow postflooding root recovery in the dryland riparian tree Eucalyptus camaldulensis subsp. refulgens. Plant Cell Environ 38: 1189-1199 
Attallah CV, Welchen E, Martin AP, Spinelli SV, Bonnard G, Palatnik JF, Gonzalez DH (2011) Plants contain two SCO proteins that are differentially involved in cytochrome c oxidase function and copper and redox homeostasis. J Exp Bot 62: 4281-4294

Beyer EM (1976) A potent inhibitor of ethylene action in plants. Plant Physiol 58: 268-271

Bhatt RM, Upreti KK, Divya MH, Bhat S, Pavithra CB, Sadashiva AT (2015) Interspecific grafting to enhance physiological resilience to flooding stress in tomato (Solanum lycopersicum L.). Sci HorticAmsterdam 182: 8-17

Bradford KJ (1983) Effects of soil flooding on leaf gas exchange of tomato plants. Plant Physiol 73: 475479

Bradford KJ, Hsiao TC, Yang SF (1982) Inhibition of ethylene synthesis in tomato plants subjected to anaerobic root stress. Plant Physiol 70: 1503-1507

Colmer TD, Voesenek LACJ (2009) Flooding tolerance: suites of plant traits in variable environments. Funct Plant Biol 36: 665-681

Drew MC, He CJ, Morgan PW (2000) Programmed cell death and aerenchyma formation in roots. Trends Plant Sci 5: 123- 127

Durack PJ, Wijffels SE, Matear RJ (2012) Ocean salinities reveal strong global water cycle intensification during 1950 to 2000. Science 336: 455-458

Else MA, Janowiak F, Atkinson CJ, Jackson MB (2009) Root signals and stomatal closure in relation to photosynthesis, chlorophyll a fluorescence and adventitious rooting of flooded tomato plants. Ann Bot 103: 313-323

FAO (2015). The impact of natural hazards and disasters on agriculture and food security and nutrition. Available at http://www.fao.org/emergencies/resources/documents/resources-detail/en/c/280784/ Gunawardena AH, Pearce DM, Jackson MB, Hawes CR, Evans DE (2001) Characterisation of programmed cell death during in aerenchyma formation induced by ethylene or hypoxia in roots of maize (Zea mays L.). Planta 212: 205-214

Hoagland DR, Arnon DI (1938) The water culture method for growing plants without soil. Calif. Agric. Exp. Stn. Bull. 347: 36-39

Ivanchenko MG, Den Os D, Monshausen GB, Dubrovsky JG, Bednárová A, Krishnan N (2013) Auxin increases the hydrogen peroxide $\left(\mathrm{H}_{2} \mathrm{O}_{2}\right)$ concentration in tomato (Solanum lycopersicum) root tips while inhibiting root growth. Ann Bot 112: 1107-1116 
Jackson MB (2002) Long-distance signalling from roots to shoots assessed: the flooding story. J Exp Bot 53: $175-181$

Jackson MB, Armstrong W (1999) Formation of aerenchyma and the processes of plant ventilation in relation to soil flooding and submergence. Plant Biol 1: 274-287

Jackson MB, Drew M (1984) Effects of flooding on growth and metabolism of herbaceous plants. In: Kozlowski TT (ed) Flooding and plant growth. Academic Press Inc, London, pp 47-128

Joshi R, Kumar P (2012) Lysigenous aerenchyma formation involves non-apoptotic programmed cell death in rice (Oryza sativa L.) roots. Physiol Mol Biol Pla 18: 1-9

Kawase M (1981) Effect of ethylene on aerenchyma development. Am J Bot 68: 651-658

Kawase M, Whitmoyer RE (1980) Aerenchyma development in waterlogged plants. Am J Bot 67: 18-22

Lanahan MB, Yen HC, Giovannoni JJ, Klee HJ (1994) The Never ripe mutation blocks ethylene perception in tomato. Plant Cell 6: 521-530

Larré CF, Fernando JA, Marini P, Bacarin MA, Peters JA (2013) Growth and chlorophyll a fluorescence in Erythrina crista-galli L. plants under flooding conditions. Acta Physiol Plant 35: 1463-1471

Liu Q, Guo X, Chen G, Zhu Z, Yin W, Hu Z. (2016) Silencing SlGID2, a putative F-box protein gene, generates a dwarf plant and dark-green leaves in tomato. Plant Physiol Biochem 109: 491-501

Liu YH, Offler CE, Ruan YL (2014) A simple, rapid, and reliable protocol to localize hydrogen peroxide in large plant organs by DAB-mediated tissue printing. Front Plant Sci 5: 745

Lombardi L, Casani S, Ceccarelli N, Galleschi L, Picciarelli P, Lorenzi R (2007) Programmed cell death of the nucellus during Sechium edule Sw. seed development is associated with activation of caspase-like proteases. J Exp Bot 58: 2949-2958

Loreti E, van Veen H, Perata P (2016) Plant responses to flooding stress. Curr Opin Plant Biol 33: 64-71

McNamara ST, Mitchell CA (1990) Adaptive stem and adventitious root responses of two tomato genotypes to flooding. Hortscience 25: 100-103

Mergemann H, Sauter M (2000) Ethylene induces epidermal cell death at the site of adventitious root emergence in rice. Plant Physiol 124: 609-614

Ni XL, Gui MY, Tan LL, Zhu Q, Liu WZ, Li CX (2019) Programmed cell death and aerenchyma formation in water-logged sunflower stems and its promotion by ethylene and ROS. Front Plant Sci 9:1928 
Parlanti S, Kudahettige NP, Lombardi L, Mensuali A, Alpi A, Perata P, Pucciariello C (2011) Distinct mechanisms for aerenchyma formation in leaf sheaths of rice genotypes displaying a quiescence or escape strategy for flooding tolerance. Ann Bot 107: 1335-1343

Petrov V, Hille J, Mueller-Roeber B, and Gechev TS (2015) ROS-mediated abiotic stress-induced programmed cell death in plants. Front Plant Sci 6: 69

Pires JF, Soprano E, Cassol B (2002) Morphophysiological changes in soybean in flooded soils. Pesqui Agropecu Bras 37: 41-50

Rocha M, Licausi F, Araujo WL, Nunes-Nesi A, Sodek L, Fernie AR, van Dongen JT (2010) Glycolysis and the tricarboxylic acid cycle are linked by alanine aminotransferase during hypoxia induced by waterlogging of Lotus japonicus. Plant Physiol 152: 1501-1513

Sasidharan R, Voesenek LACJ (2015) Ethylene-mediated acclimations to flooding stress. Plant Physiol 169: $3-12$

Seago JL, Marsh LC, Stevens KJ, Soukup A, Votrubova O, Enstone DE (2005) A re- examination of the root cortex in wetland flowering plants with respect to aerenchyma. Ann Bot 96: 565-79

Shimamura S, Yamamoto R, Nakamura, Shimada S, Komatsu S (2010) Stem hypertrophic lenticels and secondary aerenchyma enable oxygen transport to roots of soybean in flooded soil. Ann Bot 106: 277-284 Shingaki-Wells R, Millar AH, Whelan J, Narsai R (2014) What happens to plant mitochondria under low oxygen? An omics review of the responses to low oxygen and reoxygenation. Plant Cell Environ 37: 2260-2277

Shiono K, Takahashi H, Colmer TD, Nakazono M (2008) Role of ethylene in acclimations to promote oxygen transport in roots of plants in waterlogged soils. Plant Sci 175: 52-58

Steffens B, Geske T, Sauter M (2011) Aerenchyma formation in the rice stem and its promotion by $\mathrm{H}_{2} \mathrm{O}_{2}$. New Phytol 190: 369-378

Steffens B, Sauter M (2009) Epidermal cell death in rice is confined to cells with a distinct molecular identity and is mediated by ethylene and $\mathrm{H}_{2} \mathrm{O}_{2}$ through an autoamplified signal pathway. Plant Cell 21: 184-196

van Dongen JT, Licausi F (2015) Oxygen sensing and signaling. Annu Rev Plant Biol 66: 345-367

Vidoz ML, Loreti E, Mensuali A, Alpi A, Perata P (2010) Hormonal interplay during adventitious root formation in flooded tomato plants. Plant J 63: 551-562 
Vidoz ML, Mignolli F, Aispuru HT, Mroginski LA (2016) Rapid formation of adventitious roots and partial ethylene sensitivity result in faster adaptation to flooding in the aerial roots (aer) mutant of tomato. Sci Hortic-Amsterdam 201: 130-139

Visser EJW, Voesenek LACJ (2004) Acclimation to soil flooding—sensing and signal-transduction. Plant Soil 254: 197-214

Voesenek LACJ, Bailey-Serres J (2015) Flood adaptive traits and processes: an overview. New Phytol 206: $57-73$

Wample RL, Reid DM (1978) Control of adventitious root production and hypocotyl hypertrophy of sunflower (Helianthus annuus) in response to flooding. Physiol Plant 44: 351-358

Yamauchi T, Colmer TD, Pedersen O, Nakazono M (2018). Regulation of root traits for internal aeration and tolerance to soil waterlogging-flooding stress. Plant Physiol 176: 1118-1130

Yamauchi T, Tanaka A, Mori H, Takamure I, Kato K, Nakazono M (2016) Ethylene-dependent aerenchyma formation in adventitious roots is regulated differently in rice and maize. Plant Cell Environ 39: $2145-2157$

Yamauchi T, Watanabe K, Fukazawa A, Mori H, Abe F, Kawaguchi K, Oynagi A, Nakazono M (2014) Ethylene and reactive oxygen species are involved in root aerenchyma formation and adaptation of wheat seedlings to oxygen-deficient conditions. J Exp Bot 65: 261-273

Yamauchi T, Yoshioka M, Fukazawa A, Mori H, Nishizawa NK, Tsutsumi N, Yoshioka H, Nakazono M (2017) An NADPH oxidase RBOH functions in rice roots during lysigenous aerenchyma formation under oxygen-deficient conditions. Plant Cell 29: 775-790

Zabalza A, Van Dongen JT, Froehlich A, Oliver SN, Faix B, Gupta KJ, Schmälzlin E, Igal M, Orcaray L, Royuela M, Geigenberger P (2009) Regulation of respiration and fermentation to control the plant internal oxygen concentration. Plant Physiol 149: 1087-1098

Zhu J, Brown KM, Lynch JP (2010) Root cortical aerenchyma improves the drought tolerance of maize (Zea mays L.). Plant Cell Environ 33: 740-749

\section{Figure legends}

Fig. 1. Porosity development in 4-week-old tomato plants exposed to flooding stress (C: control, F: flooding). (A) Effect of different ethylene inhibitors on porosity increase in hypocotyls after 6 days of flooding. Values are the mean of 8-10 replicates \pm SEM. Asterisks indicate significant differences respect 
to flooding according to one-way ANOVA with Bonferroni's multiple comparisons test (ns $P>0.05$; ${ }^{*}<$ 0.05 ; ${ }^{* *} P<0.01 ;{ }^{* * *} P<0.001$ ). (B) Porosity development at different times after the start of flooding in control and flooded plants with or without $\mathrm{AgNO}_{3}$ treatment (C, control; F, flooding; F+Ag, flooding + $\mathrm{AgNO}_{3}$ ). Data are the mean of 8 replicates \pm SEM. Different letters indicate significant differences among treatments for each time point according to one-way ANOVA with Tukey's test $(P<0.05)$. (C) Effect of flooding on porosity of wild type (Pearson) and ethylene insensitive plants ( $\mathrm{Nr}$ ) after 6 days of treatment. Different letters indicate significant differences according to two-way ANOVA with Tukey's multiple comparison tests $(P<0.05, \mathrm{n}=8 \pm \mathrm{SEM})$.

Fig. 2. Microphotographs of hypocotyl sections of control, flooded and flooded $+\mathrm{AgNO}_{3}$ plants. Fourweek-old plants were exposed to flooding for 0 to $72 \mathrm{~h}$. Bars represent $500 \mu \mathrm{m}$.

Fig. 3. Detection of fragmented nuclei using DAPI and TUNEL staining in transversal hypocotyl sections from control, flooding and flooding $+\mathrm{AgNO}_{3}$ treatments. Four-week-old plants were subjected to flooding for 72h. Positive control (Control+) was obtained by treating sections from control plants with DNase. C, cortex; X, xylem.

Fig. 4. Dead cell detection by Evans blue staining in cortex of hypocotyls from control (A), flooded (B) and $\mathrm{AgNO}_{3}$-treated flooded (C) plants. Sections showing a sequence of cortical cell death in proximity to growing adventitious root tips (D-H) and epidermal cell death in correspondence with the emerging adventitious roots. Bars indicate $1 \mathrm{~mm}$.

Fig. 5. (A) Localization of $\mathrm{H}_{2} \mathrm{O}_{2}$ in hypocotyl sections by DAB-mediated printing. Sections of plants used as controls and flooded for $0,24,48$ and $72 \mathrm{~h}$ were pressed on a nylon membrane imbibed with a DAB solution. Brown stains indicate DAB oxidation due to the presence of $\mathrm{H}_{2} \mathrm{O}_{2}$ in epidermis, e; pith, p; xylem, $\mathrm{x}$; and c, cortex. (B) Relative expression levels of SIRBOH1 gene. Four-week-old plants were subjected to control conditions, $\mathrm{C}$; flooding, $\mathrm{F}$; and flooding $+\mathrm{AgNO}_{3}$ treatment, $\mathrm{F}+\mathrm{Ag}$. Each point is the mean of 3 replicates \pm SD. The expression level of control at $0 \mathrm{~h}$ was set as 1 . Different letters indicate significant differences at each time point according to one-way ANOVA with Tukey's multiple comparison tests $(P<$ 0.05). 
Fig. 6. Hypertrophy of flooded hypocotyls. (A) Effect of mock, exogenous ethylene (applied as ethephon) and $\mathrm{AgNO}_{3}$ on hypocotyl diameter increase of control and flooded plants. Values are the difference between the diameter at time 0 and after 6 days. Each bar represents the mean of 8 replicates \pm SEM. Different letters indicate statistical differences among treatments within control and flooded plants (oneway ANOVA, Tukey's post-test, $P<0.05$ ) whereas asterisks indicate statistical differences between control and flooded plants within each treatment by Student's t test $(P<0.05)$. (B) Increase in stem diameter over 6 days in control, flooded and flooded $+\mathrm{AgNO}_{3}$ plants. Values were obtained as the difference between the stem diameters of each plant at two consecutive time points. Each point represents the mean of 10 replicates \pm SEM. Different letters indicate significant differences among treatments for each time point according to one-way ANOVA, Tukey's post-test $(P<0.05)$. (C) Increase in stem diameter of hypocotyls of the ethylene insensitive mutant $N r$ and its wild type Pearson. Each bar represents the mean of 8 replicates \pm SEM. Different letters indicate significant differences according to two-way ANOVA with Tukey's multiple comparison tests $(P<0.05)$.

Fig. 7. Relative expression level of cell wall loosening genes. Transcripts of expansins (LeEXP1 and LeEXP2), xyloglucan endo-transglycosylase (SIXTH1) and cellulase (Cel7) were carried in control (C), flooded (F) and $\mathrm{AgNO}_{3}$-treated flooded ( $\mathrm{F}+\mathrm{Ag}$ ) plants. Each point represents the mean of 3 replicates \pm $\mathrm{SD}$. For each gene, expression value of control at time 0 was set as 1 . Different letters indicate significant differences at each time point according to one-way ANOVA with Tukey's multiple comparison tests $(P<$ 0.05).

Fig. 8. Anatomical measurements of hypocotyls of control and 72-h flooded plants. (A) Cortex area was obtained by measuring the surface comprised between vascular bundles and epidermis. (B) Cortex cell density obtained by counting the number of cells in the cortex within transects with known area. (C) Cell size was the average area of 40 to 50 cortical cells randomly selected for each biological replicate. Each bar represents the mean of 3 replicates \pm SD. Asterisks indicate significant differences according to Student's t test $(P<0.05)$. (D) Expression of the cell division marker gene (b-type cyclin, SlCycB1) in control and flooded hypocotyls during 6 days from the onset of flooding. Each point represents the mean 
of 3 replicates $\pm S D$. For each gene, expression value of control at time 0 was set as 1 . Asterisks indicate significant differences at each time point according to Student's t test $(P<0.05)$.

Fig. 9. (A) Oxygen content inside the cortex of hypocotyls of control, flooded and $\mathrm{AgNO}_{3}$-treated flooded plants. Each point is the mean of 7 replicates \pm SEM. (B) Oxygen consumption of hypocotyl segments of control, flooding and flooding $+\mathrm{AgNO}_{3}$ treatment. Each point is the mean of 4 replicates $\pm \mathrm{SEM}$. For graphs $\mathrm{A}$ and $\mathrm{B}$ different letters indicate statistical difference among treatments for each time point according to one-way ANOVA with Tukey's multiple comparison tests $(P<0.05)$. (C) Histochemical staining of COX activity in sections of control and flooded hypocotyls. Untreated sections (-DAB) and DAB-treated + potassium cyanide $(+\mathrm{DAB}+\mathrm{KCN})$ were used as controls. Black arrow tips indicate growing adventitious roots primordia across the cortex in flooded hypocotyl sections. Bars indicate $1 \mathrm{~mm}$.

Fig. 10. Schematic representation of sequential events that improve oxygenation of submerged tomato stems. Ethylene build-up around submerged hypocotyls triggers ROS accumulation, which acts as a signal for PCD-driven lysigenous aerenchyma formation. Parallelly, early ethylene-mediated induction of cell wall relaxation genes, determines cell enlargement and stem hypertrophy. Both, air-filled spaces originated by cortical cell death and wider intercellular spaces, facilitate oxygen diffusion towards submerged hypocotyls. Improved aeration would in turn enhance cell respiration and sustain adventitious root growth. 

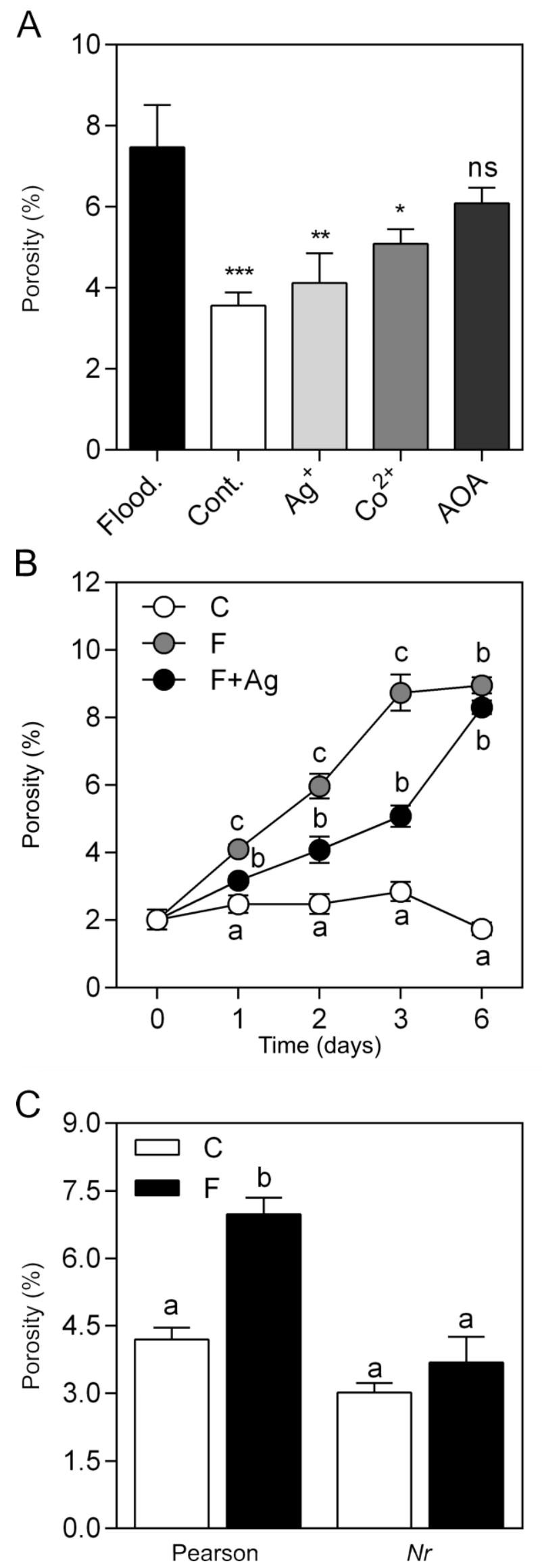


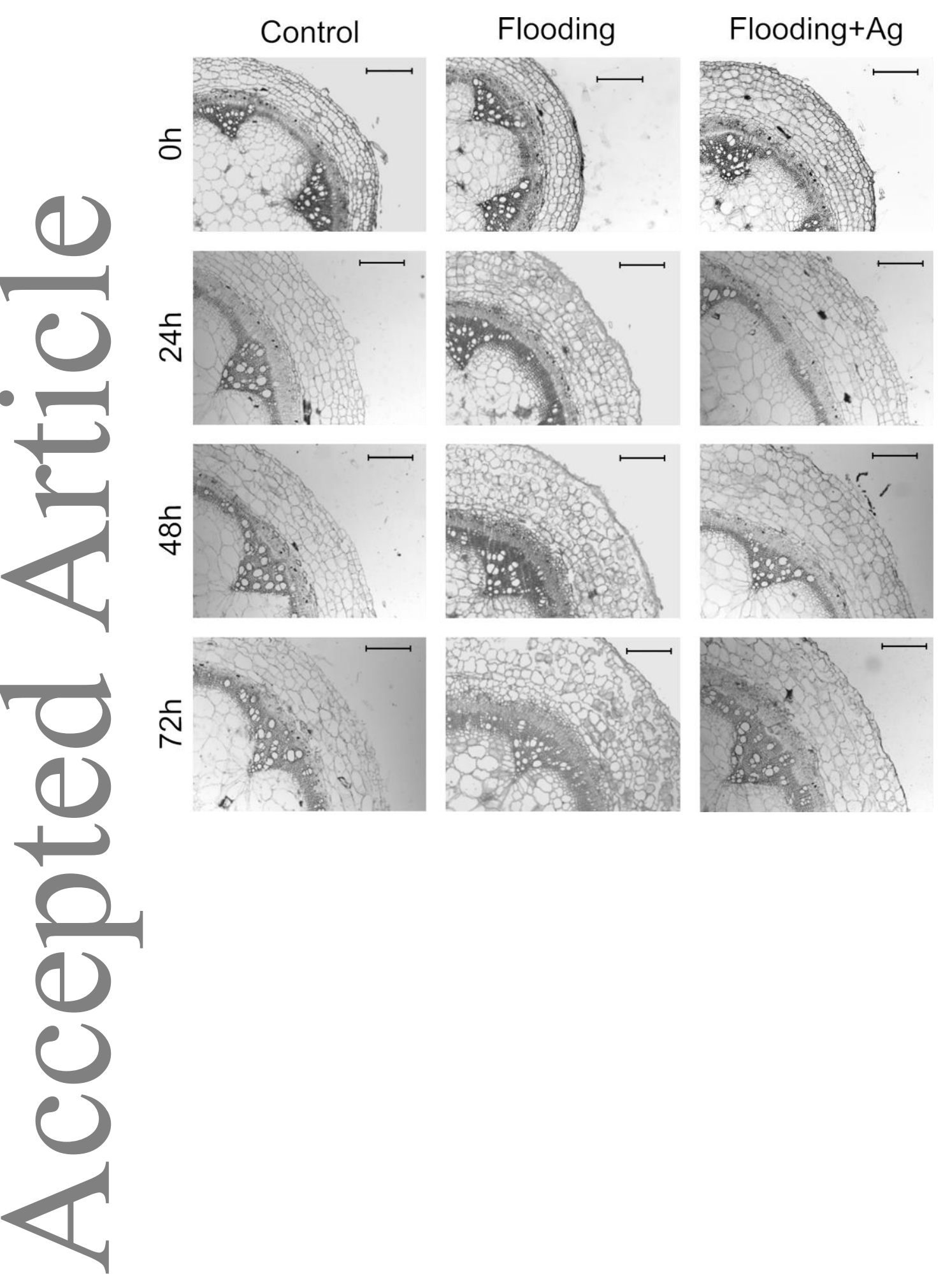



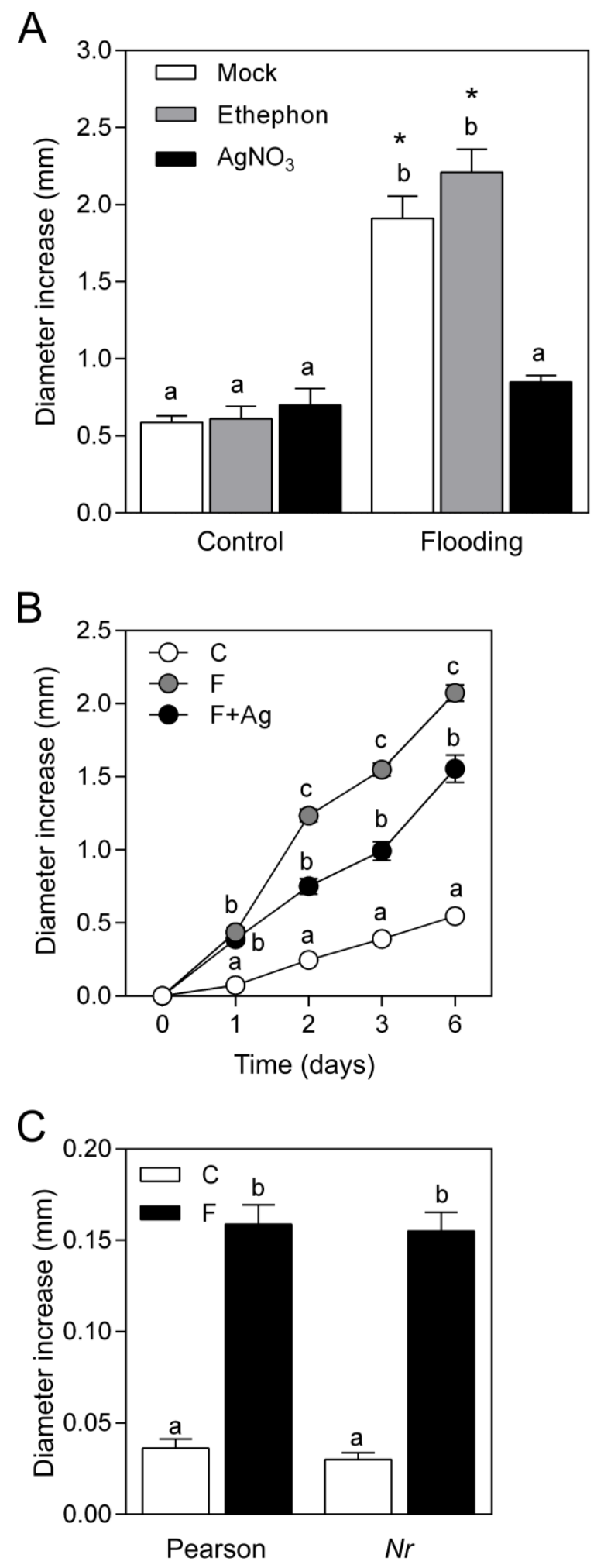

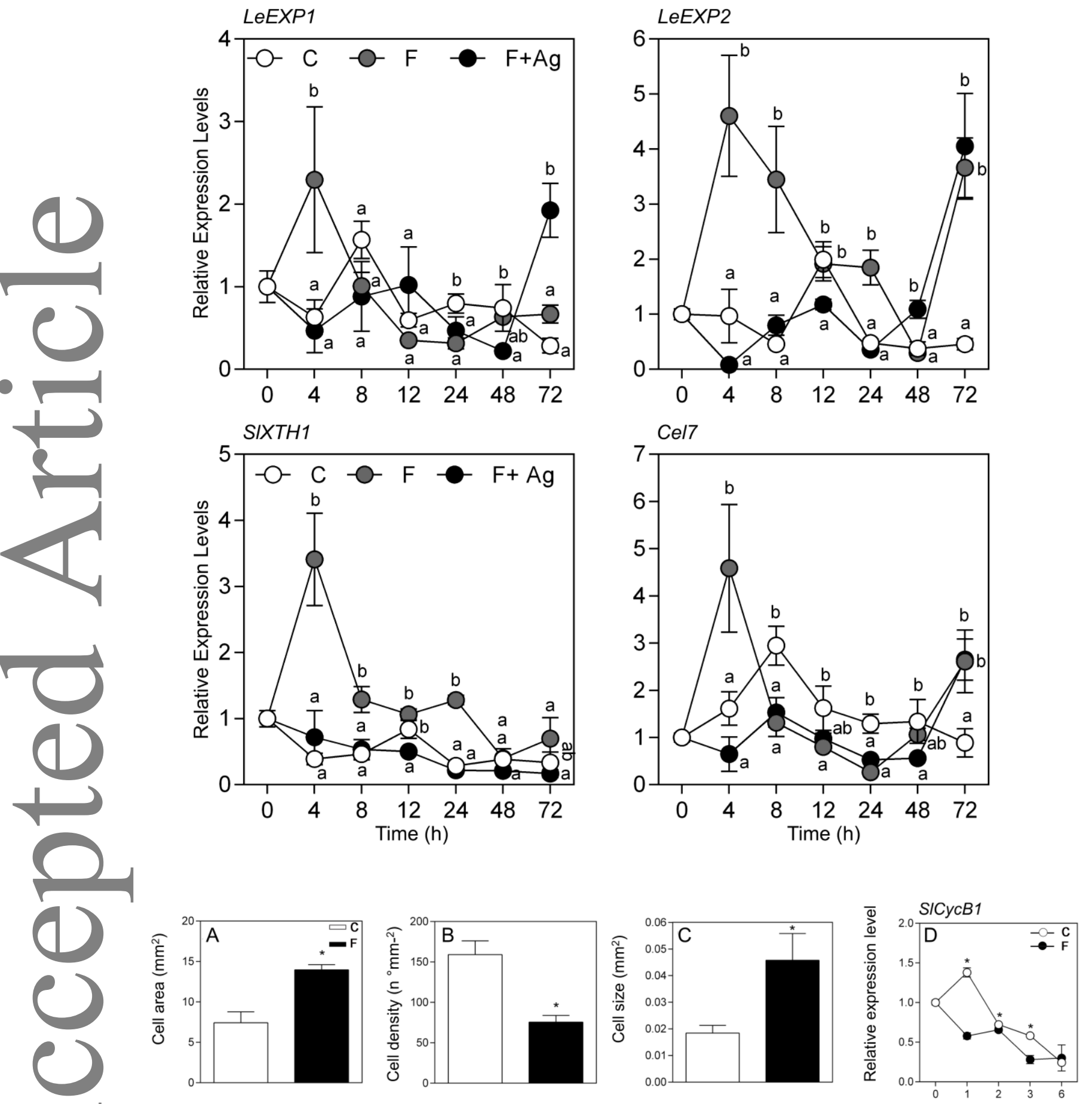

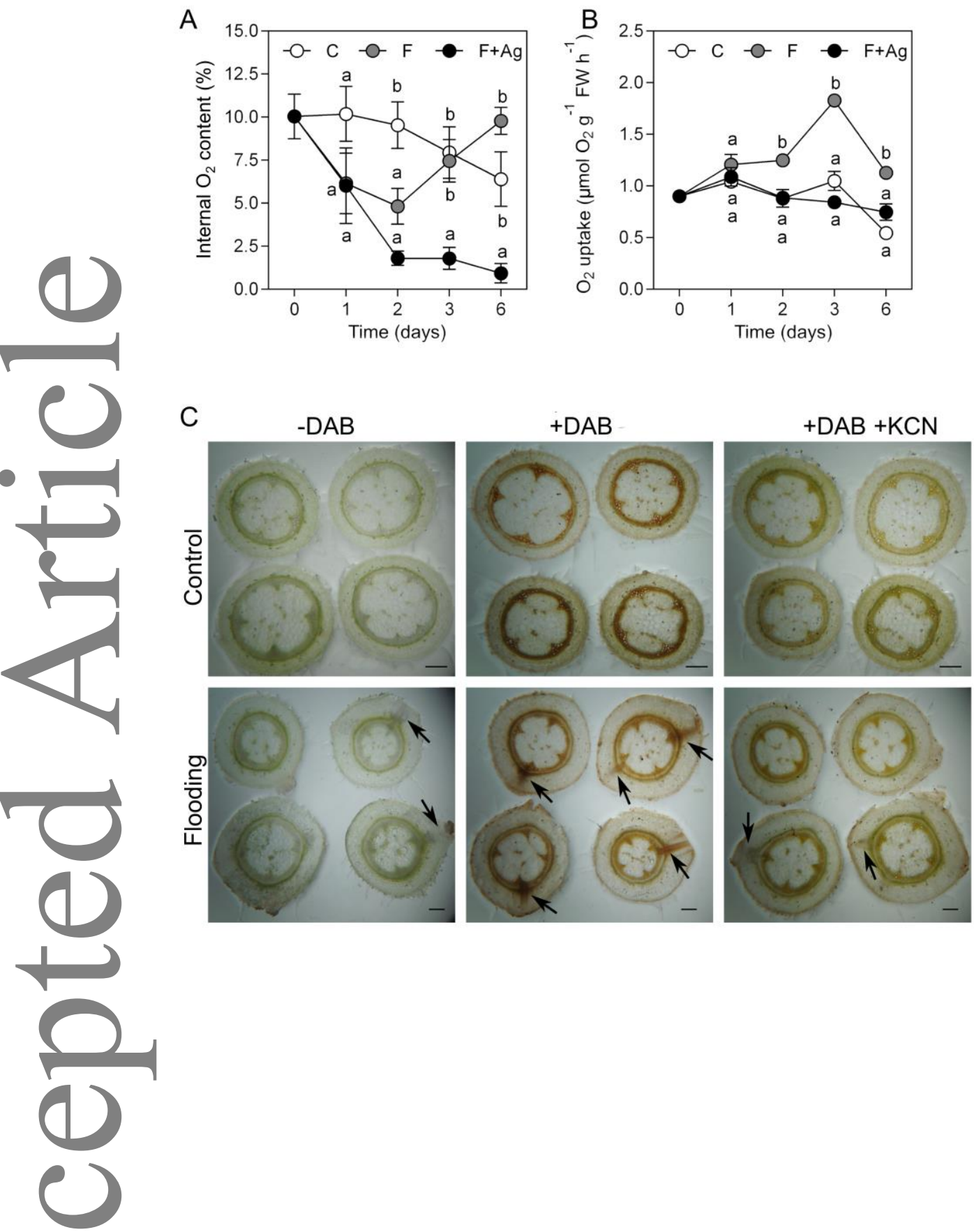

C 


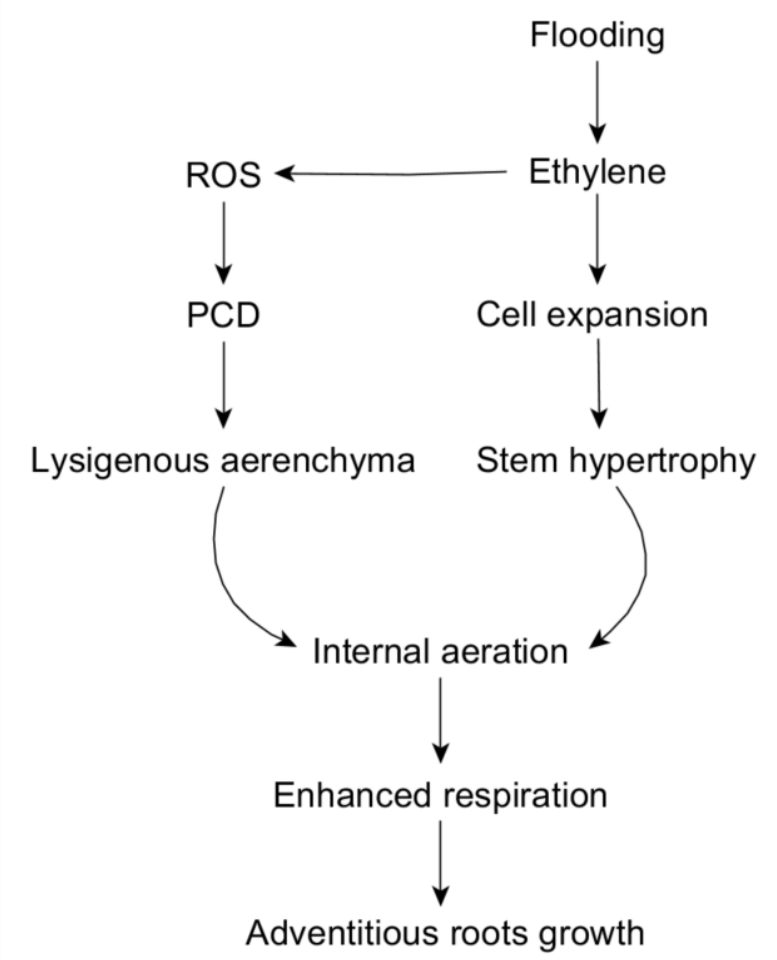

